\title{
It is time for AI to prevent unintentionally disastrous human errors
}

\author{
Ahmad Ali Abin ${ }^{1}$, Shahabedin Nabavi ${ }^{1}$, and Mohsen Ebrahimi Moghaddam ${ }^{1}$ \\ ${ }^{1}$ Shahid Beheshti University
}

June 8, 2020

\begin{abstract}
Humans can be replaced by artificial intelligence-based approaches in many applications to reduce the probability of human errors. These approaches can also help us predict some events by analyzing data that seems to be unimportant. The overwhelming crash of flight 752 of Ukrainian International Airlines by the Iranian air defense systems in the early days of 2020 has prompted us more to explain the need to use artificial intelligence to prevent such events. This study attempts to calculate the likelihood of airline hazards based on artificial intelligence to warn decision-makers of the occurrence of potential accidents before flights. As a case study, we investigate the proposed method on flight 752 to explain its usefulness in great details. This study was designed to gain further insights into the use of artificial intelligence in risk estimation and can be criticized or modified.
\end{abstract}

\section{Hosted file}

manuscript.pdf available at https://authorea.com/users/331124/articles/457844-it-is-timefor-ai-to-prevent-unintentionally-disastrous-human-errors 